\title{
A multi-criteria decision-making approach for evaluating carbon performance of suppliers in the electronics industry
}

\author{
C. W. Hsu • R. J. Kuo $\cdot$ C. Y. Chiou
}

Received: 29 June 2012/Revised: 19 February 2013/ Accepted: 13 March 2013/Published online: 17 April 2013

(C) Islamic Azad University (IAU) 2013

\begin{abstract}
Although interest in addressing environmental perspectives in supplier management is rising, incorporating the issue of carbon management into supplier selection in green supply chain is still considerably scarce. This study presents a model for evaluating carbon performance of suppliers by utilizing multiple-criteria decision-making. Through literature reviews and expert opinions, 13 criteria within carbon performance are identified for evaluating suppliers. Subsequently, the analytic network process is utilized to determine the relative weights of each criterion. Finally, the VlseKriterijumska Optimizacija I Kompromisno Resenje technique is employed to evaluate carbon performance of suppliers and compromise solution under each of the evaluation criteria. An illustrative example in an electronics company is presented to demonstrate how to select the most appropriate supplier in accordance with carbon management. To be effective in mitigating carbon risk across the supply chain, the proposed hybrid model can help firms evaluate carbon performance of suppliers for facilitating low carbon supply chain.
\end{abstract}

C. W. Hsu ( $₫)$

Department of Ecotourism, Tungnan University,

New Taipei City, Taiwan

e-mail: jcwhsu@mail.tnu.edu.tw

R. J. Kuo

Department of Industrial Management, National Taiwan

University of Science and Technology, No. 43,

Section 4, Kee-Lung Road, Taipei, Taiwan

C. Y. Chiou

Department of International Trade and Logistics,

Overseas Chinese University,

100, Chiao Kwang Road, Taichung 407, Taiwan
Keywords Analytic network process - Electronics industry · Supplier evaluation · Carbon performance · VlseKriterijumska Optimizacija I Kompromisno Resenje

\section{Introduction}

With increased awareness of climate change in the supply chain, supplier selection and evaluation with carbon performance are becoming recognized as significant in making purchasing decision (Dou and Sarkis 2010; Hsu et al. 2012a, b; Le and Lee 2011; Schoenherr et al. 2012). The World Business Council for Sustainable Development (WBCSD) and the World Resources Institute (WRI) (2009) reported that at least $80 \%$ of carbon emissions are produced in the total supply chain. The challenge for global supply chain network is selection of raw material and component suppliers in order to meet the quantity of emitted carbon dioxide (Le and Lee 2011). According to the 2010 supply chain report from the carbon disclosure project (CDP), more than half of its members surveyed said that in the future, they would cease doing business with suppliers that do not manage their carbon emissions. Some CDP members have attempted to develop a way to address the impact of the supply chain on climate change in recent times. By controlling the carbon footprint across a supply chain, Wittneben and Kiyar (2009) emphasize that greenhouse gas (GHG) emissions from suppliers require consideration to adequately assess the contributions of any business to climate change. Companies in different industry sectors are beginning to recognize the carbon issue as one of the critical factors in green supply chain management (GSCM) (Lee 2011). In the case of electronics industry, Nokia Corporation (2009) has started collaborative work with its suppliers of components and contract 
manufacturers in the area of carbon dioxide emission at the end of 2007. Later, Dell (2009) and HP Corporation (2009) published aggregated supply chain GHG emissions through supplier engagement to report GHG emissions and establish reduction targets. If suppliers fail to meet these requirements with Dell, suppliers can be impacted on the ranking and may be diminished potentially on ability to compete for Dell's business (Dell 2009). Therefore, more effective evaluation of suppliers can lead to markedly improved carbon management along the supply chain (CDP 2011). As noted previously, companies are increasingly requiring their suppliers to manage their carbon emissions as a condition for doing business with them.

Supplier selection and evaluation is a multi-criteria decision-making (MCDM) problem (Huang and Keskar 2007; Liaoa and Rittscherb 2007; Tuzkaya et al. 2009), which provides an effective framework for supplier comparison based on the evaluation of multiple conflict criteria (Shyur and Shih 2006). Literature related to MCDM has proposed several supplier selection and evaluation methodologies, some familiar examples of systematic analysis include analytic hierarchy process (AHP) (Tam and Tummala 2001), fuzzy QFD (Bevilacqua et al. 2006), analytic network process (ANP) (Shyur and Shih 2006; Gencer and Gürpinar 2007; Hsu and Hu 2009; Zhu et al. 2010; Kuo and Lin 2011), case-based reasoning (CBR) systems (Choy et al. 2003), and multiple objective programming (Zhu 2004). However, the application of the mathematical programming model to supplier selection may have problems in including qualitative criteria, particularly for supplier partnership policies (Ghodsypour and O'Brien 2001). Furthermore, the computational complexities inherent in multiple objective programming frequently prohibit consideration of many crucial attributes for supplier selection (Chan and Kumar 2007). To overcome this problem, either the weighting model of the AHP or the ANP can be used since it is more useful for treating qualitative factors than other models such as mathematical programming models. The ANP technique is now widely embraced in supplier selection to provide good insights in terms of feedback systematic and interdependencies property (Bayazit 2006; Gencer and Gürpinar 2007; Hsu and $\mathrm{Hu}$ 2009; Zhu et al. 2010; Pang and Bai 2011). Moreover, ANP is not practically usable if the number of alternatives is huge, so that this may cause fatigue in decision-making (Briand 1998). Another favorable technique for solving MCDM problem in supplier selection is the VlseKriterijumska Optimizacija I Kompromisno Resenje (VIKOR) (Chen and Wang 2009; Liou and Chuang 2010; Hsu et al. 2012a, b), which focuses on ranking and selecting from a set of alternatives, and determines compromise solutions for a problem with conflicting criteria, and helps the decision-makers to reach a final decision (Opricovic and Tzeng 2007).
Although there are a number of researches in the field of supplier selection and evaluation using a hybrid MCDM model, supplier evaluation specifically considering carbon performance using ANP and VIKOR method has rarely been found. According to the characteristics of problem and the advantage of aforementioned two techniques, this study proposes a hybrid MCDM model based on the ANP that is utilized to determine relative weight. And then, the VIKOR with ANP weights is proposed for evaluating carbon performance of supplier to discover the performance scores and gaps. An illustrated example of electronics manufacturer in Taiwan has been demonstrated the proposed framework for facilitating appropriate supplier selection in terms of carbon management. Given the fact that the proposed model indeed paves a new way for managers to manage and evaluate suppliers who are capable of having competence in carbon management. This study was conducted in Tungnan University in New Taipei City, Taiwan, from January to June 2012.

\section{Materials and methods}

\section{Analytic network process}

The ANP is the general form of the AHP, which has been used in MCDM to release restrictions associated with hierarchical structures (Huang et al. 2005). AHP can integrate qualitative information and quantitative values (Meade and Sarkis 1998) and can handle MCDM problems (Saaty 1980). Nevertheless, AHP has disadvantages. It does not sufficiently consider interdependencies (Chung et al. 2005), and it does not allow for the integrated dynamic modeling of environments (Meade and Sarkis 1998). As a result, Saaty (1980) introduced a super-matrix approach in dealing with the interdependencies among clusters. Currently, this approach is called the ANP method. The advantages of the ANP include the abilities to incorporate dependencies and feedback using a hierarchical decision network, to represent and analyze interactions, and to synthesize their mutual effects through a single logical procedure (Sarkis and Sundarraj 2002). Additionally, ANP can be used as a decision analysis tool to solve multicriteria supplier selection problems that contain interdependencies (Bayazit 2006) and provide systematic feedback (Gencer and Gürpinar 2007). ANP modeling thus better fits the problem examined in this study, and offers the advantage of providing a systematic approach to supplier evaluation as well as previous studies (Bayazit 2006; Shyur and Shih 2006; Gencer and Gürpinar 2007; Hsu and Hu 2009; Zhu et al. 2010).

In this study, the matrix manipulation relies on the concept of Saaty and Takizawa (1986), as well as the study 
conducted by Shyur and Shih (2006), instead of Saaty's original super matrix for ease of understanding. The detailed description of the matrix deployment process of the ANP method can be found in the work of Saaty and Takizawa (1986) and Shyur and Shih (2006). Some essential steps are as follows.

\section{Step 1: determining the weights of criteria} within independence

Without assuming the interdependence between criteria, the decision-maker is asked to respond to the relative weighting of each criterion via a paired comparison matrix. A scale of 1-9 is used to compare the two components. A score of 1 indicates that the two components have equal importance, whereas a score of 9 indicates the overwhelming dominance of the considered component (row component) over the comparison component (column component). If the impact of one component is weaker than that of its comparison component, it will be scored from 1 to $1 / 9$, with 1 indicating indifference and $1 / 9$ indicating the overwhelming dominance of the column component over the row component. Once the pair-wise comparisons are completed, the local vector $w_{1}$ is computed as the unique solution of

$A w_{1}=\lambda_{\max } w_{1}$

where $\lambda_{\max }$ is the largest eigenvalue of pair-wise comparison matrix $A$. All acquired vectors are normalized to get the e-vectors $w_{2}$ of these relative importance weights.

\section{Step 2: determining the weights of criteria}

within interdependence

Considering the interdependence among criteria, the decision-maker is asked to answer the question for evaluating the interdependencies related to "which criterion will influence criterion $a$ more: $b$ or $c$ ", and "what is the relative impact of criterion $a$ compared to criterion $b$ or $c$ ". Various pair-wise comparison matrices are constructed for each criterion. The e-vector from these matrices is thus used to form interdependence weight matrix $M$, where zeros are assigned to the eigenvector weights of the criteria with independent relationship.

\section{Step 3: synthesizing the weights}

By synthesizing the results of step 1 and 2, the relative weights of criteria considering interdependence can be acquired as follows:

$w_{c}=M w_{2}$

\section{VIKOR}

The compromise ranking method (known as VIKOR) has been introduced as one applicable technique to implement within MCDM (Opricovic 1998), which is based on the basic concept of the positive-ideal solution and negativeideal solution to evaluate the standard of different project in the competition from MCDM model (Opricovic and Tzeng 2004). The positive-ideal solution indicates the alternative with the highest value, while the negative-ideal solution indicates the alternative with the lowest value. VIKOR focuses on ranking and selecting from a set of alternatives, and determines compromise solutions for a problem with conflicting criteria, and helps the decisionmakers to reach a final decision (Opricovic and Tzeng 2007). Various studies regarded VIKOR as a suitable technique to evaluate each alternative for each criterion function (Opricovic and Tzeng 2004; Liou and Chuang 2010). The compromise ranking algorithm VIKOR has the following steps (Tzeng et al. 2002; Opricovic and Tzeng 2007; Liou and Chuang 2010).

\section{Step 1: determine the best and the worst values}

The best value is $f_{j}^{*}$ and the worst value is $f_{j}^{-}$in evaluation criteria. Those values can be computed by Eqs. (3) and (4).

$f_{j}^{*}=\max _{i} f_{i j}, \quad i=1,2, \ldots, m$

$f_{j}^{-}=\min _{i} f_{i j}, \quad i=1,2, \ldots, m$

where, $f_{j}^{*}$ is the positive-ideal solution for the $j$ th criterion, and $f_{j}^{-}$is the negative-ideal solution for the $j$ th criterion.

\section{Step 2: calculate the distance}

This step is to compute the distance from each alternative to the positive-ideal solution. The value can be computed by Eqs. (5) and (6).

$\begin{aligned} S_{i} & =\sum_{j=1}^{n} w_{j}\left(\left|f_{j}^{*}-f_{i j}\right|\right) /\left(\left|f_{j}^{*}-f_{j}^{-}\right|\right) \\ Q_{i} & =\max _{i}\left\{w_{j}\left(\left|f_{j}^{*}-f_{i j}\right|\right) /\left(\left|f_{j}^{*}-f_{j}^{-}\right|\right) \quad j=1,2, \ldots, n\right\}\end{aligned}$

where, $w_{j}$ represents the weights of the criteria from ANP, $S_{i}$ shows the mean of group utility and represents the distance of the $i$ th alternative achievement to the positiveideal solution, and $Q_{i}$ represents the maximal regret of each alternative. 
Step 3: calculate the index value

There index values are defined as:

$R_{i}=v\left[\frac{S_{i}-S^{*}}{S^{-}-S^{*}}\right]+(1-v)\left[\frac{Q_{i}-Q^{*}}{Q^{-}-Q^{*}}\right]$

where, $S^{*}=\min S_{i}$ (or setting the best $S^{*}=0$ ), $S^{-}=$ $\max _{i} S_{i}$ (or setting the worst $S^{-}=1$ ), $Q^{*}=\min _{i} Q_{i}$ (or setting the best $Q^{*}=0$ ), and $Q^{-}=\max _{i} Q_{i}$ (or setting the worst $Q^{-}=1$ ). Equation (7) can be re-written as $R_{i}=v S_{i}+(1-v) Q_{i}$, when $S^{*}=0$ and $Q^{*}=0$ (i.e., all criteria have been achieve to the aspire level) and $S^{-}=1$ and $Q^{-}=1$ (i.e., the worst situation), where $v$ is introduced as a weight for the strategy of maximum group utility, whereas $1-v$ is the weight of the individual regret. In Eq. (7), when $v=1$, it represents decision-making process that could use the strategy of maximum group utility. On the other hand, when $v=0$, it represents decision-making process that could use the strategy of minimum individual regret. In general, $v=0.5$ would be used if the decision process is concerned about both maximum group utility and individual regret (Tzeng et al. 2002; Liou and Chuang 2010). The compromise solution is determined by VIKOR, and it can be accepted by the decision-makers based on a maximum group utility of the majority and a minimum of the individual regret of the opponent.

\section{Results and discussion}

An illustrated case of electronics manufacturer

Since suppliers of brand name companies, such as Nokia, Dell and HP are mainly from Taiwan, one of the most industrialized countries in the Asia-Pacific region and home to a large number of electrical and electronics manufacturers involved in original equipment manufacturing (OEM) and original design manufacturing (ODM) (Chien and Shih 2007; Hsu and $\mathrm{Hu} 2008$ ), these electronics companies are subject to customer requests for carbon management either at organization or product level. Hence, the main risks and pressures OEMs and ODMs faced with their suppliers include carbon management in the green supply chain. Therefore, both types of manufacturers must select suppliers capable of delivering both high-quality products and competent carbon management. To solve this question, a comprehensive model of carbon management for supplier selection is necessary for managers to determining appropriate suppliers as a long-term collaborative partnership in the green supply chain.

As pointed out by Shah and Siddiqui (2006), the case study is an appropriate methodology for addressing the phenomena in which the research has lesser or no control. The case company in this study has embraced and is interested in incorporating carbon management into supplier evaluation and selection because it suffers pressure from buyers, and it has become a CDP member of carbon management in the supply chain. The case company would like to implement a systematic method of evaluating suppliers based on competency of carbon management because of worldwide trend for increasing environmental regulations on climate change initiatives.

\section{Step 1: identifying evaluation criteria}

The first step in hybrid decision model is to construct the decision structure of supplier selection problem and to identify the relevant criteria related to carbon performance and alternatives developed. Through interviews with three senior supply chain and environmental management representatives from the case company, a framework of 13 criteria for carbon performance were recognized in literature (Cogan et al. 2008; CDP 2010; Hsu et al. 2012a, b) for evaluating suppliers, which is acceptance by senior managers of criteria and their clusters which are presented in Table 1. This model has three levels (see Fig. 1). The second level consists of 13 criteria of carbon performance. The third level is the alternative in the illustrated case.

\section{Step 2: determining the interrelationship among criteria}

After 13 criteria of carbon performance for supplier evaluation were recognized from literature, a simple correlation matrix questionnaire with three experts was applied to determine the interrelationship among the criteria. A questionnaire was prepared to inquire about the relationship of one criterion to another and to synergize the interrelationship among the criteria. As illustrated in Table $2, C_{5}$ was affected by $C_{1}$ and $C_{9}$ based on expert opinion.

\section{Step 3: calculating the weights by ANP}

By considering the interdependent relationships exist in the real supplier selection and evaluation environment, ANP method in this study is utilized to solve the dependence and feedback problem of each criterion. To determine the relative importance of criteria for the objective of selecting the best supplier, the decision-maker is asked to respond to the weights of all criteria without assuming the interdependence between criteria. After the pair-wise comparison matrices are developed, a vector of priorities (i.e., eigenvector or eigenvector) in each matrix is calculated and subsequently normalized to sum to 1.0 or $100 \%$. This study utilized a two-stage algorithm to calculate the 
Table 1 Criteria for supplier selection in carbon performance

\begin{tabular}{|c|c|}
\hline Criteria & Description \\
\hline Carbon governance $\left(C_{1}\right)$ & $\begin{array}{l}\text { Carbon management for firms has been incorporated into their board and executive structures to ensure } \\
\text { that the strategy is effectively turned into action }\end{array}$ \\
\hline Carbon policy $\left(C_{2}\right)$ & $\begin{array}{l}\text { By integrating carbon policies into their procurement departments, company can facilitate low carbon } \\
\text { management practices across the organization }\end{array}$ \\
\hline Carbon reduction targets $\left(C_{3}\right)$ & $\begin{array}{l}\text { Setting targets to reduce carbon emissions has become as critical strategy for firm to facilitating low } \\
\text { carbon management }\end{array}$ \\
\hline Carbon risk assessment $\left(C_{4}\right)$ & $\begin{array}{l}\text { Carbon risk assessment can greatly enhance the awareness and understanding of firm on how to carry } \\
\text { out the strategies of climate change mitigation }\end{array}$ \\
\hline $\begin{array}{l}\text { Training-related carbon management } \\
\left(C_{5}\right)\end{array}$ & $\begin{array}{l}\text { To be effective in carbon management implementation, relevant education and training for employees } \\
\text { need to be launched to promote environmental consciousness }\end{array}$ \\
\hline Life cycle cost management $\left(C_{6}\right)$ & $\begin{array}{l}\text { While incorporating life cycle cost management into carbon emissions mitigation, companies can get } \\
\text { an insightful analysis of carbon management from a cost-effective perspective }\end{array}$ \\
\hline Measures of carbon management $\left(C_{7}\right)$ & Companies can take internal and external measures to mitigate carbon emissions \\
\hline $\begin{array}{l}\text { Involvement in initiatives for carbon } \\
\text { management }\left(C_{8}\right)\end{array}$ & $\begin{array}{l}\text { Working together with NGOs, governments, or other companies on carbon initiatives, firms are } \\
\text { encouraged to measures, manage, disclose, and reduce their carbon emissions in mitigating carbon } \\
\text { risks }\end{array}$ \\
\hline $\begin{array}{l}\text { Management systems of carbon } \\
\text { information }\left(C_{9}\right)\end{array}$ & $\begin{array}{l}\text { Management systems of carbon information for firms can effectively collect carbon emissions data and } \\
\text { manage business risks related to carbon issues }\end{array}$ \\
\hline Supplier collaboration $\left(C_{10}\right)$ & $\begin{array}{l}\text { Carbon emissions are mainly produced in the total supply chain, collaborative initiatives with suppliers } \\
\text { on carbon management practices and technology can effectively facilitate low carbon supply chain } \\
\text { and operation }\end{array}$ \\
\hline Carbon accounting and inventory $\left(C_{11}\right)$ & $\begin{array}{l}\text { Carbon accounting and inventory is essentially an initial step in developing strategies and evaluating } \\
\text { progress for controlling carbon emissions in the operations of a company, product, and supply chain }\end{array}$ \\
\hline Carbon verification $\left(C_{12}\right)$ & $\begin{array}{l}\text { External verification of carbon inventories with third party is becoming increasingly important in order } \\
\text { to demonstrate organization's positive approach to climate change publicly }\end{array}$ \\
\hline Carbon disclosure and report $\left(C_{13}\right)$ & $\begin{array}{l}\text { For effective communication with stakeholders, reporting and disclosure of carbon emissions is an } \\
\text { important first step toward a successful climate change strategy and green image promotion }\end{array}$ \\
\hline
\end{tabular}

Fig. 1 The framework of supplier evaluation

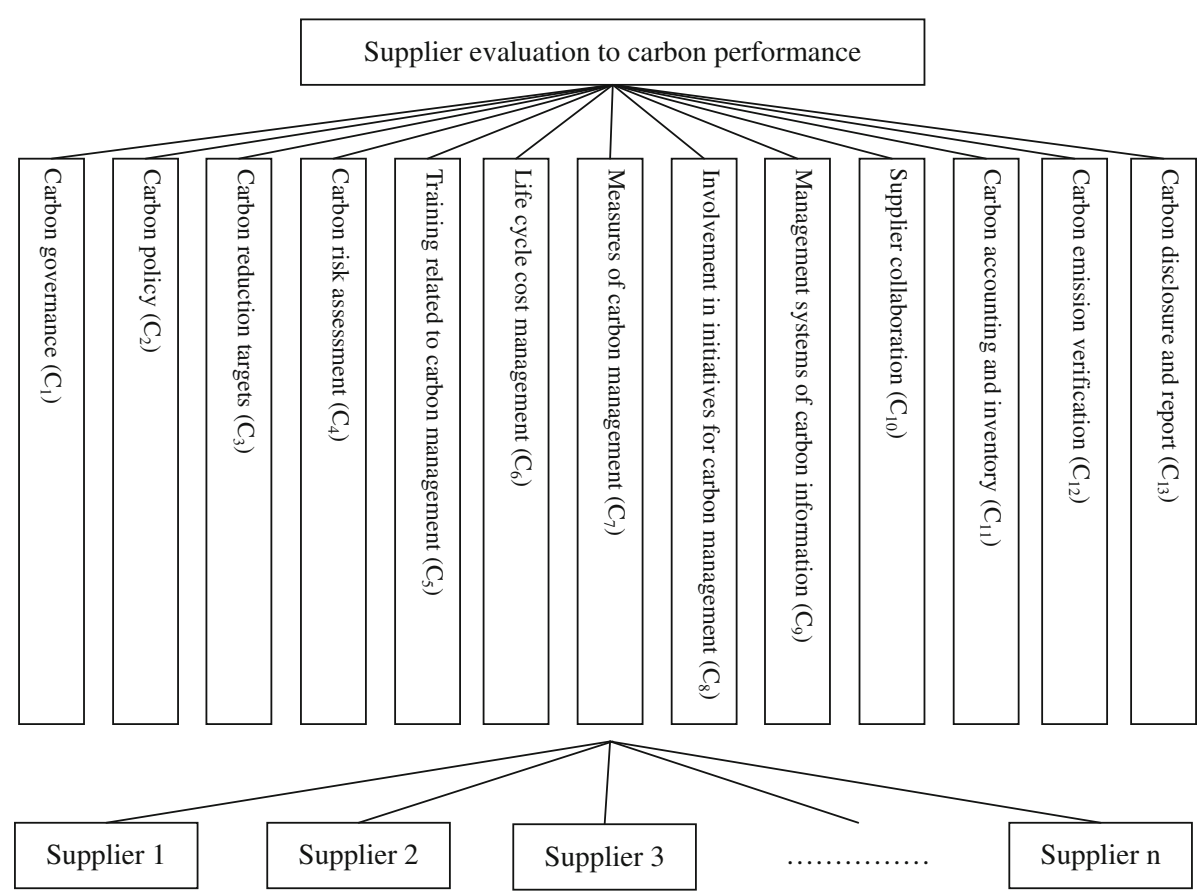


e-vector, which first adds the value in each column of the matrix and then separates each entry in each column by the total of that column; the normalized matrix is acquired through meaningful comparison among components. The evaluation results are presented in Table 3 ; the normalized eigenvector can be generated as $w_{2}=\left(C_{1}, C_{2}, C_{3}, C_{4}, C_{5}, C_{6}\right.$, $\left.C_{7}, C_{8}, C_{9}, C_{10}, C_{11}, C_{12}, C_{13}\right)=(0.080,0.076,0.065,0.073$, $0.059,0.128,0.049,0.091,0.061,0.062,0.080,0.064,0.113$ ).

The interdependence between criteria is now considered based on Table 2, and weight matrix of criteria is defined as $w_{2}$. In total, 13 pair-wise comparison matrices are generated and the decision-makers examine the relative for each criterion. The normalized eigenvector for these matrices is calculated, as shown in Table 4.

By obtaining the synthesis of the results, the relative importance of the evaluation criteria considering interdependence can be obtained as follows:
Table 2 The correlation between criteria

\begin{tabular}{|c|c|c|c|c|c|c|c|c|c|c|c|c|c|}
\hline & $C_{1}$ & $C_{2}$ & $C_{3}$ & $C_{4}$ & $C_{5}$ & $C_{6}$ & $C_{7}$ & $C_{8}$ & $C_{9}$ & $C_{10}$ & $C_{11}$ & $C_{12}$ & $C_{13}$ \\
\hline$C_{1}$ & & () & () & () & (?) & () & () & () & () & () & (?) & () & () \\
\hline$C_{2}$ & (?) & & () & () & & () & () & () & (?) & (?) & & (?) & () \\
\hline \multicolumn{14}{|l|}{$C_{3}$} \\
\hline \multicolumn{14}{|l|}{$C_{4}$} \\
\hline$C_{5}$ & (?) & () & () & () & & (?) & () & () & () & () & () & () & () \\
\hline$C_{6}$ & () & () & () & & & & & & & ○) & & & \\
\hline$C_{7}$ & () & () & () & () & & (?) & & & & () & & & \\
\hline$C_{8}$ & () & () & () & & & & & & & (?) & & & \\
\hline$C_{9}$ & () & () & () & () & () & () & () & () & & (?) & (?) & () & () \\
\hline$C_{10}$ & () & () & (?) & (?) & & (?) & () & & & & & & \\
\hline$C_{11}$ & () & () & () & () & & () & () & & & () & & (?) & \\
\hline$C_{12}$ & () & () & () & & & () & () & & & () & & & \\
\hline$C_{13}$ & () & () & & & & & & & & (?) & & & \\
\hline
\end{tabular}

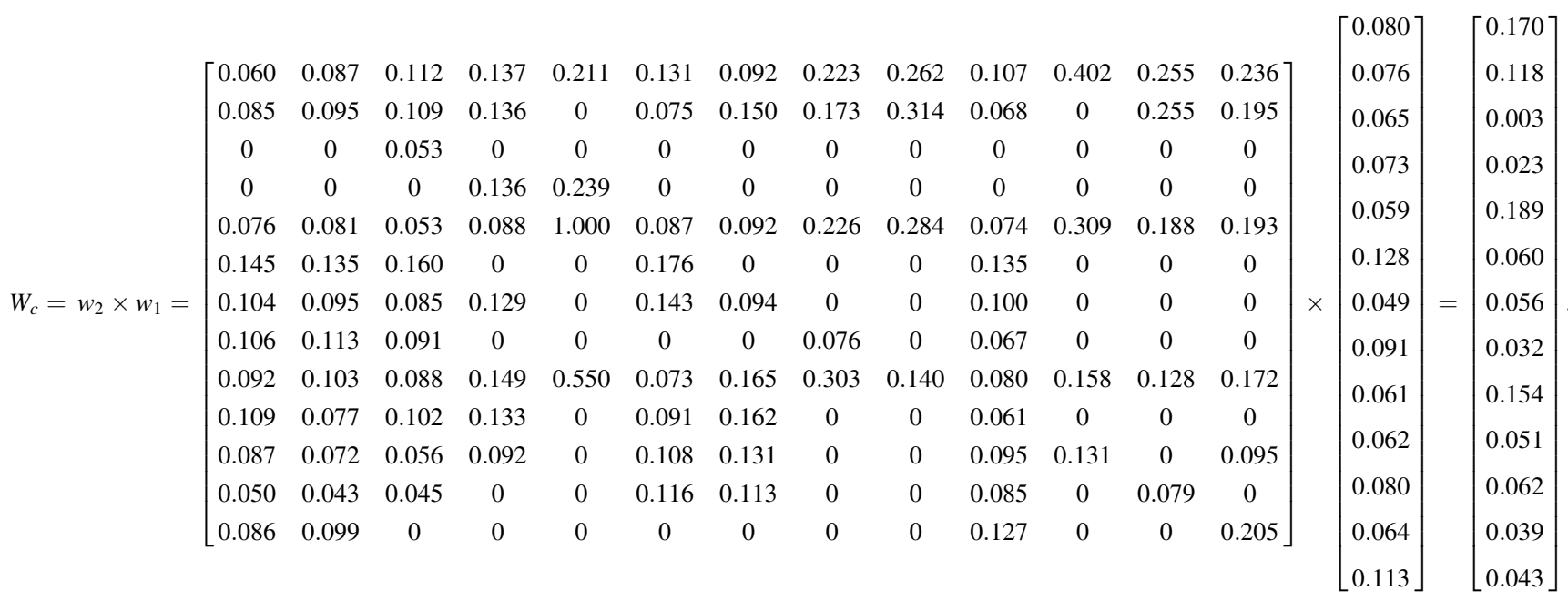

As for the relative weights of criteria for evaluating carbon performance of supplier, "training related to carbon management $\left(C_{5}\right)$ " $(0.189)$, "carbon governance $\left(C_{1}\right)$ " (0.170), "management systems of carbon information $\left(C_{9}\right)$ " $(0.154)$, and "carbon policy $\left(C_{2}\right)$ " $(0.118)$ are the top four significant evaluation criteria, which comprised more than $60 \%$ of the overall weighting.

\section{Step 4: compromise ranking by VIKOR}

After the weights of criteria are determined by ANP, the VIKOR method is employed to evaluate carbon performance of supplier selection (Table 5). There are three managers in case company conducting the assessment who are responsible in the field of supplier management. By considering the easy-to-use proposed model in case company, in this research, $v$ value of VIKOR is set to 0.5 based on both maximum group utility and individual regret within experts' opinion. Since $R_{i}$ represents the gap between the alternative and ideal solution, it is observed that $S_{1}$ contains the smallest gap in terms of the value of VIKOR. Summing these values for each of the alternatives provides in Table $6, S_{1}$ thus was the best supplier. 
Table 3 Comparison matrix for the evaluation criteria

\begin{tabular}{lllllllllllllll}
\hline$w_{1}$ & $C_{1}$ & $C_{2}$ & $C_{3}$ & $C_{4}$ & $C_{5}$ & $C_{6}$ & $C_{7}$ & $C_{8}$ & $C_{9}$ & $C_{10}$ & $C_{11}$ & $C_{12}$ & $C_{13}$ & e-Vector \\
\hline$C_{1}$ & 1.000 & 1.442 & 1.000 & 0.843 & 0.843 & 1.000 & 1.186 & 1.289 & 1.326 & 1.710 & 1.326 & 0.920 & 0.693 & 0.080 \\
$C_{2}$ & 0.693 & 1.000 & 1.913 & 1.000 & 1.186 & 0.843 & 1.186 & 1.710 & 1.326 & 1.216 & 0.843 & 0.843 & 0.405 & 0.076 \\
$C_{3}$ & 1.000 & 0.523 & 1.000 & 0.843 & 0.843 & 0.754 & 1.186 & 1.442 & 1.119 & 1.000 & 1.000 & 1.000 & 0.405 & 0.065 \\
$C_{4}$ & 1.186 & 1.000 & 1.186 & 1.000 & 1.000 & 0.693 & 1.710 & 0.822 & 0.693 & 0.693 & 1.442 & 1.442 & 0.843 & 0.073 \\
$C_{5}$ & 1.186 & 0.843 & 1.186 & 1.000 & 1.000 & 0.405 & 0.693 & 0.585 & 1.000 & 1.442 & 0.693 & 0.693 & 0.481 & 0.059 \\
$C_{6}$ & 1.000 & 1.186 & 1.326 & 1.442 & 2.466 & 1.000 & 4.217 & 1.913 & 2.466 & 1.442 & 2.466 & 3.557 & 1.000 & 0.128 \\
$C_{7}$ & 0.843 & 0.843 & 0.843 & 0.585 & 1.442 & 0.237 & 1.000 & 0.585 & 1.000 & 0.693 & 0.481 & 0.481 & 0.405 & 0.049 \\
$C_{8}$ & 0.776 & 0.585 & 0.693 & 1.216 & 1.710 & 0.523 & 1.710 & 1.000 & 1.442 & 1.710 & 2.466 & 2.466 & 1.186 & 0.091 \\
$C_{9}$ & 0.754 & 0.754 & 1.289 & 1.442 & 1.000 & 0.405 & 1.000 & 0.693 & 1.000 & 1.216 & 0.693 & 0.693 & 0.585 & 0.061 \\
$C_{10}$ & 0.585 & 0.822 & 1.442 & 1.442 & 0.693 & 0.693 & 1.442 & 0.585 & 0.822 & 1.000 & 0.585 & 0.585 & 0.776 & 0.062 \\
$C_{11}$ & 0.754 & 1.186 & 1.000 & 0.693 & 1.442 & 0.405 & 2.080 & 0.405 & 1.442 & 1.710 & 1.000 & 2.924 & 1.000 & 0.080 \\
$C_{12}$ & 1.087 & 1.186 & 1.000 & 0.693 & 1.442 & 0.281 & 2.080 & 0.405 & 1.442 & 1.710 & 0.342 & 1.000 & 0.342 & 0.064 \\
$C_{13}$ & 1.442 & 2.466 & 2.466 & 1.186 & 2.080 & 1.000 & 2.466 & 0.843 & 1.710 & 1.289 & 1.000 & 2.924 & 1.000 & 0.113 \\
\hline
\end{tabular}

Table 4 Degree of relative impact for evaluation criteria

\begin{tabular}{|c|c|c|c|c|c|c|c|c|c|c|c|c|c|}
\hline$w_{2}$ & $C_{1}$ & $C_{2}$ & $C_{3}$ & $C_{4}$ & $C_{5}$ & $C_{6}$ & $C_{7}$ & $C_{8}$ & $C_{9}$ & $C_{10}$ & $C_{11}$ & $C_{12}$ & $C_{13}$ \\
\hline$C_{1}$ & 0.060 & 0.087 & 0.112 & 0.137 & 0.211 & 0.131 & 0.092 & 0.223 & 0.262 & 0.107 & 0.402 & 0.255 & 0.236 \\
\hline$C_{2}$ & 0.085 & 0.095 & 0.109 & 0.136 & & 0.075 & 0.150 & 0.173 & 0.314 & 0.068 & & 0.255 & 0.195 \\
\hline$C_{3}$ & & & 0.053 & & & & & & & & & & \\
\hline$C_{4}$ & & & & 0.136 & 0.239 & & & & & & & & \\
\hline$C_{5}$ & 0.076 & 0.081 & 0.100 & 0.088 & 1.000 & 0.087 & 0.092 & 0.226 & 0.284 & 0.074 & 0.309 & 0.188 & 0.193 \\
\hline$C_{6}$ & 0.145 & 0.135 & 0.160 & & & 0.176 & & & & 0.135 & & & \\
\hline$C_{7}$ & 0.104 & 0.095 & 0.085 & 0.129 & & 0.143 & 0.094 & & & 0.100 & & & \\
\hline$C_{8}$ & 0.106 & 0.113 & 0.091 & & & & & 0.076 & & 0.067 & & & \\
\hline$C_{9}$ & 0.092 & 0.103 & 0.088 & 0.149 & 0.550 & 0.073 & 0.165 & 0.303 & 0.140 & 0.080 & 0.158 & 0.128 & 0.172 \\
\hline$C_{10}$ & 0.109 & 0.077 & 0.102 & 0.133 & & 0.091 & 0.162 & & & 0.061 & & & \\
\hline$C_{11}$ & 0.087 & 0.072 & 0.056 & 0.092 & & 0.108 & 0.131 & & & 0.095 & 0.131 & 0.095 & \\
\hline$C_{12}$ & 0.050 & 0.043 & 0.045 & & & 0.116 & 0.113 & & & 0.085 & & 0.079 & \\
\hline$C_{13}$ & 0.086 & 0.099 & & & & & & & & 0.127 & & & 0.205 \\
\hline
\end{tabular}

A hybrid MCDM model of supplier selection is proposed in this study, it provides a systematically analytic approach to evaluate supplier performance of carbon management. With respect to the importance and priority of criteria from ANP, moreover, it is observed that training-related carbon management $\left(C_{5}\right)$ is the most significant criterion in evaluating carbon performance followed by carbon governance $\left(C_{1}\right)$ and management systems of carbon information $\left(C_{9}\right)$. It implies that these three criteria play a crucial role in influencing the decision of supplier selection. Such information can be extremely helpful for managers to recognize areas where suppliers ought to improve. Then, it is easy for a company to engage in supplier development and help the suppliers improve on their efforts to better carbon performance. Obviously this hybrid model is capable of having competence in handing the interrelationship among criteria and determining the priority criteria for facilitating supplier management in terms of carbon performance.

Additionally, supplier selection associated with carbon management performance is based on the gap from the ideal solution that differs from the conventional aggregated method, i.e., the simple additive weighting (SAW) method. The advantage of VIKOR for proposed model is to use an aggregating function to determine a solution with the shortest distance from the ideal solution and farthest distance from the negative-ideal solution. Results of the study reveal that $S_{1}>S_{3}>S_{2}>S_{4}>S_{5}$ in terms of overall score of carbon management, where $S_{1}$ is considered as most appropriate supplier. Company can use the concept of maximum group utility and minimum individual regret to select the real "closest to the ideal" solution as well as supplier selection and evaluation with carbon management. In this study, the $v=0.5$ is adopted 
Table 5 Performance matrix of suppliers on each criterion

\begin{tabular}{|c|c|c|c|c|c|c|}
\hline Criteria & Weights & $S_{1}$ & $S_{2}$ & $S_{3}$ & $S_{4}$ & $S_{5}$ \\
\hline Carbon governance $\left(C_{1}\right)$ & 0.170 & 0.0000 & 0.0800 & 0.0400 & 0.1000 & 0.0600 \\
\hline Carbon policy $\left(C_{2}\right)$ & 0.118 & 0.0278 & 0.0417 & 0.0000 & 0.0556 & 0.0556 \\
\hline Carbon reduction targets $\left(C_{3}\right)$ & 0.003 & 0.0000 & 0.0010 & 0.0007 & 0.0023 & 0.0017 \\
\hline Carbon risk assessment $\left(C_{4}\right)$ & 0.023 & 0.0107 & 0.0133 & 0.0080 & 0.0187 & 0.0187 \\
\hline Training-related carbon management $\left(C_{5}\right)$ & 0.189 & 0.0316 & 0.0316 & 0.0789 & 0.0789 & 0.0631 \\
\hline Life cycle cost management $\left(C_{6}\right)$ & 0.060 & 0.0210 & 0.0490 & 0.0350 & 0.0490 & 0.0420 \\
\hline Measures of carbon management $\left(C_{7}\right)$ & 0.056 & 0.0067 & 0.0333 & 0.0200 & 0.0200 & 0.0200 \\
\hline Involvement in initiatives for carbon management $\left(C_{8}\right)$ & 0.032 & 0.0151 & 0.0189 & 0.0151 & 0.0151 & 0.0189 \\
\hline Management systems of carbon information $\left(C_{9}\right)$ & 0.154 & 0.0906 & 0.1087 & 0.0543 & 0.0543 & 0.1087 \\
\hline Supplier collaboration $\left(C_{10}\right)$ & 0.051 & 0.0060 & 0.0180 & 0.0120 & 0.0240 & 0.0240 \\
\hline Carbon accounting and inventory $\left(C_{11}\right)$ & 0.062 & 0.0144 & 0.0217 & 0.0072 & 0.0289 & 0.0361 \\
\hline Carbon verification $\left(C_{12}\right)$ & 0.039 & 0.0091 & 0.0182 & 0.0091 & 0.0228 & 0.0273 \\
\hline Carbon disclosure and report $\left(C_{13}\right)$ & 0.043 & 0.0100 & 0.0250 & 0.0100 & 0.0350 & 0.0350 \\
\hline
\end{tabular}

Table 6 Result of the VIKOR analysis

\begin{tabular}{llll}
\hline Supplier & $S_{i}$ & $Q_{i}$ & VIKOR $\left(R_{i}\right)$ \\
\hline$S_{1}$ & 0.2429 & 0.5556 & $0.3942(1)$ \\
$S_{2}$ & 0.4603 & 0.6667 & $0.6066(3)$ \\
$S_{3}$ & 0.2903 & 0.5556 & $0.4179(2)$ \\
$S_{4}$ & 0.5046 & 0.7778 & $0.6237(4)$ \\
$S_{5}$ & 0.5110 & 0.7778 & $0.6269(5)$ \\
\hline
\end{tabular}

as basic to trade-off between maximum group utility and minimum individual regret for evaluating supplier. While company emphasize on the maximum group utility, then $v=1$ would be used; on the contrary, $v=0$ would be used if the company is concerned about minimum individual regret. It implies that VIKOR method is useful and feasible for the manager to select the suitable weights $(v)$ in the decision-making process of supplier selection with various requirements.

After discussing the findings with three experts of the case company, carbon performance for supplier selection and evaluation has been regarded as an emerging parameter for maintaining the long-term collaborative relationship. Based on opinions of experts, accordingly, the carbon management scorecard (CMS) should be launched and further integrated into the quarterly business review (QBR) in terms of 13 criteria within the proposed MCDM model in this study. By incorporating the carbon issue into procurement policies, suppliers will be required to perform a preliminary self-assessment or to be audited throughout the CMS questionnaire. After that, the company can obtain a draft understanding on the capability of carbon management for its suppliers that help them identify and prioritize specific carbon risks. Based on the CMS model, suppliers can engage their own first tier suppliers in the same way to help understand, prioritize, and address specific carbon risks. Also, this hybrid model can enable the road map of supplier management to effectively mitigate and manage carbon risk derived from supply chain.

\section{Conclusion}

The supply chain-based conceptual framework and operational model to incorporate carbon management into supplier selection have been presented. By identifying the related criteria of carbon management activities for the proposed framework, a hybrid model of integration of ANP and VIKOR methods was applied to an electronics company for facilitating supplier management in the emerging field of carbon management. Without appropriate consideration of suppliers' ability to accomplish with climate change, company may be risky and lead to supply chain disrupted. Studies have shown that companies suffering supply chain disruptions experienced 33-40\% lower stock returns relative to their industry benchmarks (Hendricks and Singhal 2005). By offering a comprehensive model in this study, not only can firms evaluate suppliers, but can also engage in collaboration with suppliers on capability building to improve their efforts of carbon management.

Compared with the previous investigations, the proposed method may have the following contributions to supplier selection and evaluation. First, a new hybrid MCDM model for evaluating suppliers with emphasis on carbon performance has been developed. Such a framework has never being found in the previous literature. And from the illustrated example this model shows its potential advantage in selecting suitable suppliers in terms of carbon management. Second, a hybrid model of integration of 
ANP and VIKOR methods was applied in supplier evaluation and it is rarely found from the previous studies. After identification of problem structure and interrelationships between criteria, the key criteria influencing supplier selection have been recognized. ANP can capture both quantitative and qualitative criteria and reflect more realistic results among decision attributes and alternatives owing to the existence of interdependent relationships in the real supplier selection and evaluation environment. Therefore, ANP modeling can serve as a new method and offer insights to managers in selecting suppliers systematically. Also, the hybrid model considers both maximum group utility and individual regret to measure the gaps between alterative and ideal solutions, which can strengthen the ability to conduct carbon performance assessment of suppliers under lack of quantitative information. Third, a company which wants to incorporate carbon issue into supplier management can adopt the presented model or road map of suppliers' carbon management to its needs.

Although the results obtained from this research are satisfactory, there still a room for improvement. The outcome of the carbon performance model with the MCDM method conducted in this study is exclusively determined by three managers of the case company; it is worthwhile to increase the number of participating firms for construing a more generalized model of suppliers' carbon management for mastering carbon risk. In responding to the preference of decision-makers in assigning precise numerical values, the fuzzy ANP and fuzzy VIKOR can be utilized in future research. Furthermore, the proposed method can be extended and developed into intelligent software to illustrate the practical application.

Acknowledgments The authors would like to thank the National Science Council of Taiwan for financially supporting this research under grant NSC 99-2815-C-236-005-H.

\section{References}

Bayazit O (2006) Use of analytic network process in vendor selection decisions. Benchmark Int J 13(5):566-579

Bevilacqua M, Ciarapica FE, Giacchetta G (2006) A fuzzy-QFD approach to supplier selection. J Purch Supply Manag 12(1): $14-27$

Briand LC (1998) COTS evaluation and selection. Proceeding of the international conference on software maintenance, Bethesda, pp 222-223

Carbon Disclosure Project (CDP) (2010) Carbon disclosure project: supply chain report 2010. London

Carbon Disclosure Project (CDP) (2011) Carbon disclosure project: supply chain report 2011-Migrating to a low carbon economy through leadership and collaboration. London

Chan TS, Kumar N (2007) Global supplier development considering risk factors using fuzzy extended AHP-based approach. Omega Int J Manag Sci 35(4):417-431
Chen LY, Wang TC (2009) Optimizing partners' choice in IS/IT outsourcing projects: the strategic decision of fuzzy VIKOR. Int J Prod Econ 120:233-242

Chien MK, Shih LH (2007) An empirical study of the implementation of green supply chain management practices in the electrical and electronic industry and their relation to organizational performances. Int J Environ Sci Tech 4(3):383-394

Choy KL, Lee WB, Lo V (2003) Design of a case based intelligent supplier relationship management system-the integration of supplier rating system and product coding system. Expert Syst Appl 25:87-100

Chung SH, Lee AHI, Pearn WL (2005) Analytic network process (ANP) approach for product mix planning in semiconductor fabricator. Int J Prod Econ 96:15-36

Cogan D, Good M, Kantor G, McAteer E (2008) Corporate governance and climate change: consumer and technology companies. Ceres, Inc., Boston

Dell (2009) Inspire and innovation-achievements in corporate responsibility. http://i.dell.com/sites/content/corporate/corp-comm/ en/Documents/Dell_CR_Summary_Report_FINAL.pdf. Accessed 15 August 2010

Dou Y, Sarkis J (2010) A joint location and outsourcing sustainability analysis for a strategic offshoring decision. Int J Prod Res 48(2): 567-592

Gencer C, Gürpinar D (2007) Analytic network process in supplier selection: a case study in an electronic firm. Appl Math Model 31(11):2475-2486

Ghodsypour SH, O'Brien C (2001) The total cost of logistics in supplier, under conditions of multiple sourcing, multiple criteria and capacity constraint. Int J Prod Econ 73:15-27

Hendricks K, Singhal V (2005) An empirical analysis of the effect of supply chain disruptions on long-run stock price performance and equity risk of the firm. Prod Oper Manag 14(1):25-53

HP (2009) Changing the equation-the impact of HP global citizenship in 2009-and beyond 2009. http://www.hp.com/ hpinfo/globalcitizenship/09gcreport/pdf/fy09_brochure.pdf. Assessed 15 March 2011

Hsu CW, Hu AH (2008) Green supply chain management in the electronic industry. Int J Environ Sci Tech 5(2):205-216

Hsu CW, Hu AH (2009) Applying hazardous substance management to supplier selection using analytic network process. J Clean Prod 17(2):255-264

Hsu CH, Wang FK, Tzeng GH (2012a) The best vendor selection for conducting the recycling material based on a hybrid MCDM model combining DANP with VIKOR. Resour Conserv Recycl. doi:10.1016/j.resconrec.2012.02.009

Hsu CW, Kuo TC, Chen SH, Hu AH (2012b) Using DEMATEL to develop a carbon management model of supplier selection in green supply chain management. J Clean Prod. doi:10.1016/ j.jclepro.2011.09.012

Huang S, Keskar H (2007) Comprehensive and configurable metrics for supplier selection. Int J Prod Econ 105(2):510-523

Huang JJ, Tzeng GH, Ong CS (2005) Multidimensional data in multidimensional scaling using the analytic network process. Pattern Recogn Lett 26:755-767

Kuo RJ, Lin YJ (2011) Supplier selection using analytic network process and data envelopment analysis. Int J Prod Res 50(11):2852-2863

Le TPN, Lee TR (2011) Model selection with considering the $\mathrm{CO}_{2}$ emission alone the global supply chain. J Intell Manuf. doi: 10.1007/s10845-011-0613-6

Lee KH (2011) Integrating carbon footprint into supply chain management: the case of Hyundai motor company (HMC) in the automobile industry. J Clean Prod 19(11):1216-1223

Liaoa Z, Rittscherb J (2007) A multi-objective supplier selection model under stochastic demand conditions. Int J Prod Econ 105(1):150-159 
Liou JH, Chuang YT (2010) Developing a hybrid multi-criteria model for selection of outsourcing providers. Exp Syst Appl 37(5): 3755-3761

Meade L, Sarkis J (1998) Strategic analysis of logistics and supply chain management systems using the analytical network process. Transp Res E-Log 34(3):201-215

Nokia (2009) Nokia 2009 sustainability report. http://www.nokia. com/NOKIA_COM_1/Corporate_Responsibility/Sustainability_ report_2009/pdf/sustainability_report_2009.pdf. Accessed 15 August 2010

Opricovic S (1998) Multicriteria optimization of civil engineering systems. Faculty of Civil Engineering, Belgrade

Opricovic S, Tzeng GH (2004) Compromise solution by MCDM methods: a comparative analysis of VIKOR and TOPSIS. Eur J Oper Res 156(2):445-455

Opricovic S, Tzeng GH (2007) Extended VIKOR method in comparison with outranking methods. Eur J Oper Res 178(2): 514-529

Pang B, Bai S (2011) An integrated fuzzy synthetic evaluation approach for supplier selection based on analytic network process. J Intell Manuf. doi:10.1007/s10845-011-0551-3

Saaty TL (1980) The analytic hierarchy process. McGraw-Hill, New York

Saaty TL, Takizawa M (1986) Dependence and independence: from linear hierarchies to nonlinear networks. Eur J Oper Res 26: 229-237

Sarkis J, Sundarraj RP (2002) Hub location at digital equipment corporation: a comprehensive analysis of qualitative and quantitative factors. Eur J Oper Res 137:336-347
Schoenherr T et al (2012) Research opportunities in purchasing and supply management. Int J Prod Res 50:4556-4579

Shah MH, Siddiqui FA (2006) Organizational critical success factors in adoption of e-banking at the Woolwich bank. Int J Inform Manag 26(6):442-456

Shyur HJ, Shih HS (2006) A hybrid MCDM model for strategic vendor selection. Math Comput Model 44:749-761

Tam MCY, Tummala VMR (2001) An application of the AHP in vendor selection of a telecommunications system. Omega Int $\mathrm{J}$ Manag Sci 29:171-182

Tuzkaya G, Ozgen A, Ozgen D, Tuzkaya UR (2009) Environmental performance evaluation of suppliers: a hybrid fuzzy multicriteria decision approach. Int J Environ Sci Tech 6(3):477-490

Tzeng GH, Teng MH, Chen JJ, Opricovic S (2002) Multicriteria selection for a restaurant location in Taipei. Int J Hosp Manag 21:171-187

Wittneben BF, Kiyar D (2009) Climate change basics for managers. Manag Decis 47(7):1122-1132

World Business Council for Sustainable Development (WBCSD) and World Resources Institute (WRI) (2009) The greenhouse gas protocol initiative: scope 3 accounting and reporting standard, review draft. WBCSD and WRI, Geneva

Zhu J (2004) A buyer-seller game model for selection and negotiation of purchasing bids: extensions and new models. Eur J Oper Res 134:150-156

Zhu QH, Dou Y, Sarkis J (2010) A portfolio-based analysis for green supplier management using the analytical network process. Supply Chain Manag 15(4):306-319 